\title{
Novel infectious agents causing uveitis
}

\author{
Moncef Khairallah • Soon Phaik Chee • \\ Sivakumar R. Rathinam - Sonia Attia . \\ Venu Nadella
}

Received: 19 May 2009/Accepted: 27 July 2009/Published online: 27 August 2009

(C) Springer Science+Business Media B.V. 2009

\begin{abstract}
In any patient with uveitis, an infectious cause should be ruled out first. The differential diagnosis includes multiple well-known diseases including herpes, syphilis, toxoplasmosis, tuberculosis, bartonellosis, Lyme disease, and others. However, clinician should be aware of emerging infectious agents as potential causes of systemic illness and also intraocular inflammation. Air travel, immigration, and globalization of business have overturned traditional pattern of geographic distribution of infectious diseases, and therefore one should work locally but think globally. This review recapitulates the systemic and ocular manifestations of several emergent infectious diseases relevant to the
\end{abstract}

M. Khairallah $(\bowtie) \cdot$ S. Attia

Department of Ophthalmology, Fattouma Bourguiba

University Hospital, 5019 Monastir, Tunisia

e-mail: moncef.khairallah@rns.tn

S. P. Chee

Singapore National Eye Centre, Singapore, Singapore

\section{S. P. Chee}

Department of Ophthalmology, Yong Loo Lin School of Medicine, National University of Singapore, Singapore, Singapore

S. P. Chee

Singapore Eye Research Institute, Singapore, Singapore

S. R. Rathinam · V. Nadella

Aravind Eye Hospital \& PG Institute of Ophthalmology, Madurai, Tamil Nadu, India ophthalmologist including Rickettsioses, West Nile virus infection, Rift valley fever, Dengue fever, and Chikungunya. Retinitis, chorioretinitis, retinal vasculitis, and optic nerve involvement have been associated with these emergent infectious diseases. The diagnosis of any of these infections is usually based on pattern of uveitis, systemic symptoms and signs, and specific epidemiological data and confirmed by detection of specific antibody in serum. A systematic ocular examination, showing fairly typical fundus findings, may help establish an early clinical diagnosis, which allows prompt, appropriate management.

Keywords Uveitis - Infection ·

Emergent infectious diseases - Rickettsioses ·

West Nile virus · Rift valley fever .

Dengue fever - Chikungunya - Retinitis ·

Chorioretinitis - Retinal vasculitis .

Optic nerve involvement

\section{Introduction}

Infectious causes should always be considered in all patients with uveitis. The differential diagnosis include multiple well-known diseases, including herpes, syphilis, toxoplasmosis, tuberculosis, bartonellosis, Lyme disease, and others. However, clinician should be aware of emerging infectious agents as potential causes of systemic illness and also 
intraocular inflammation. Air travel, immigration, and globalization of business have overturned traditional pattern of geographic distribution of infectious diseases, and therefore one should work locally but think globally.

The purpose of this article is to review the systemic and ocular manifestations of several emergent infectious diseases relevant to the ophthalmologist including Rickettsioses, West Nile virus infection, Rift valley fever, Dengue fever, and Chikungunya.

\section{Rickettsioses}

\section{Epidemiology}

Rickettsioses are zoonoses due to obligate intracellular small gram-negative bacteria. Most of them are transmitted to humans by the bite of contaminated arthropods, such as ticks. Rickettsial agents are classified into three major categories: the spotted fever group, the typhus group, and the scrub typhus [1,2].

The spotted fever group includes Mediterranean spotted fever (MSF), Rocky Mountain spotted fever (RMSF), and numerous other rickettsioses. MSF, also called "boutonneuse" fever or tick-borne rickettsiosis, which is caused by the organism Rickettsia (R.) conorii, is prevalent in Mediterranean countries and Central Asia, including India. Rocky Mountain spotted fever, which is caused by $R$. rickettsii, is endemic in parts of North, Central, and South America, especially in the south-eastern and southcentral United States. The other multiple rickettsial species belonging to the spotted fever group vary in their geographic distribution. Epidemic typhus, which is caused by the organism $R$. prowazekii, is usually encountered in areas of crowded population with poor hygiene conditions, as occurs during wars and natural disasters. Murine typhus, which is caused by $R$. typhi, is found worldwide in warm-climate countries. Scrub typhus, which is caused by Orienta tsutsugamushi, is a zoonosis found in the Far East [1, 2].

Systemic disease

A rickettsial disease should be suspected, during spring or summer, in the presence of the triad of high fever, headache and general malaise, and skin rash in a patient living in or traveling back from a region endemic for rickettsioses. A local skin lesion, termed "tache noire" (black spot) may develop at the site of arthropod bite in MSF and several other rickettsioses. A history of outdoor activities, occupational exposure, or tick attachment is frequent $[1,2]$.

Ocular disease

Ocular involvement is common in patients with rickettsiosis, but since it is frequently asymptomatic and self-limited, it may be easily overlooked [3, 4]. However, rickettsial ocular disease may be associated with ocular complaints, such as decreased vision, scotoma, floaters, or redness. Retinitis, retinal vascular involvement, and optic disc changes are the most common ocular findings, but numerous other manifestations may occur.

\section{Retinitis}

It is observed in at least $30 \%$ of patients with acute MSF [4]. It presents in the form of white retinal lesions, typically adjacent to retinal vessels (Fig. 1A). These lesions may vary in number, size, and topography. An associated mild or moderate vitreous inflammation is commonly observed. Fluorescein angiography showed early hypofluorescence and late staining of large acute white retinal lesions and isofluorescence (Fig. 1B, C) or moderate hypofluorescence of small active retinal lesions throughout the whole phase of dye transit [4]. Serous retinal detachment, accurately detected by optical coherence tomography (OCT), frequently accompanies large foci of rickettsial retinitis (Fig. 1D).

There are reports of multiple small white retinal lesions in other rickettsioses, including RMSF, Queensland tick typhus, and murine typhus [5-11]. Multiple retinal lesions similar to those seen in multiple white dot syndrome (MEWDS) have been reported [12, 13].

Rickettsial retinitis has a self-limited evolution in most patients, with resolution of white retinal lesions with or without scarring in several weeks.

\section{Retinal vascular involvement}

Numerous retinal vascular lesions may occur in patients with rickettsial disease. They include focal or diffuse vascular sheathing, vascular leakage, intraretinal, white-centered, or subretinal hemorrhages, and 
Fig. 1 A Fundus

photograph of the left eye of a patient with

Mediterranean spotted fever shows multifocal retinitis, with white retinal lesions of various sizes adjacent to retinal vessels, and retinal hemorrhages. Fluorescein angiography $(\mathbf{B}, \mathbf{C})$ shows early hypofluorescence and late staining of large retinal lesions, retinal vascular leakage, optic disc staining, and blocked fluorescence due to retinal hemorrhages. D OCT shows increased internal reflectivity and posterior shadowing due to retinitis, retinal thickening, serous retinal detachment, and thickened posterior hyaloid
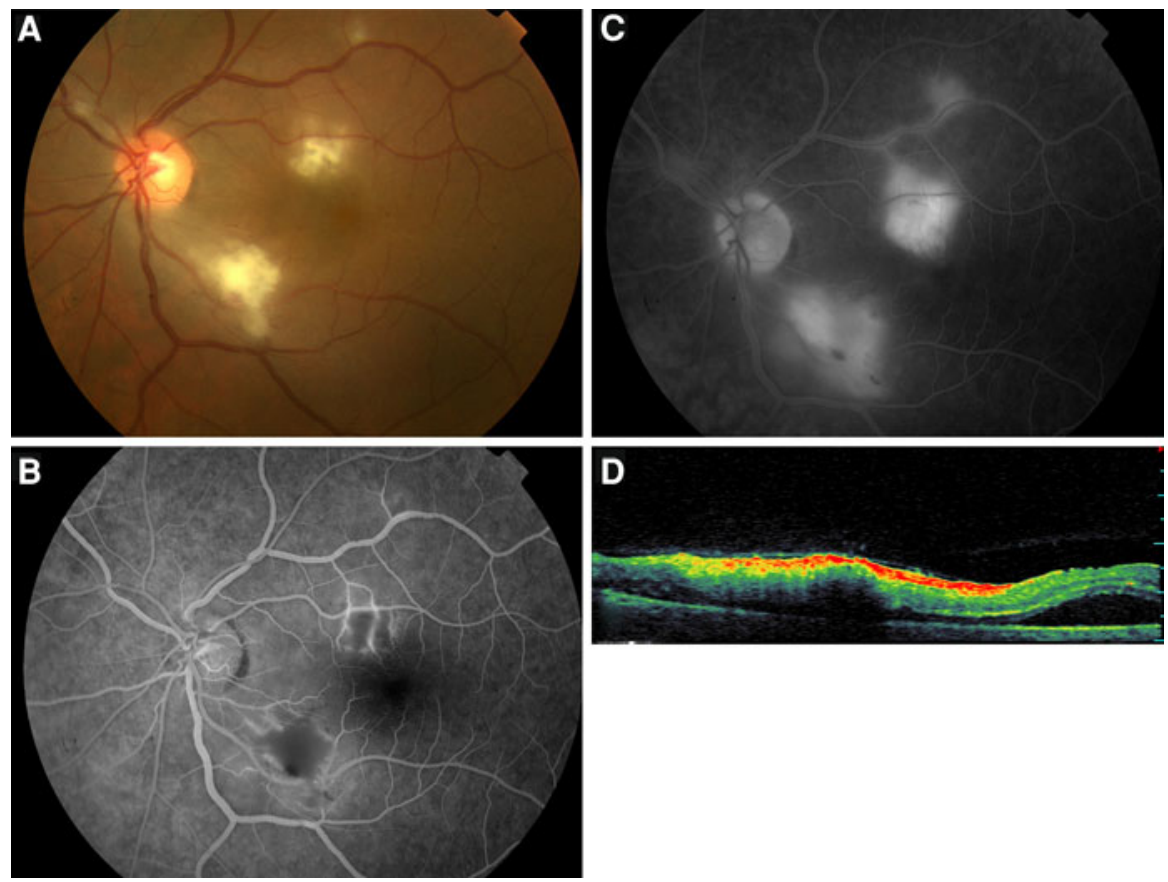

retinal vascular occlusions associated with transient or permanent visual loss, including branch and central artery occlusion, and branch retinal vein occlusion or subocclusion [3, 4, 14-17].

\section{Other retinochoroidal changes}

They include serous retinal detachment, cystoid macular edema, macular star, and hypofluorescent choroidal lesions on fluorescein and indocyanine green angiography $[4,18]$.

A case of endogenous endophthalmitis caused by $R$. conorii was reported recently [19].

\section{Optic nerve involvement}

Optic disc involvement, with or without associated visual loss, has been described in association with rickettsial infection, including optic disc edema, optic disc staining, optic neuritis, neuroretinitis, and ischemic optic neuropathy [3, 4, 18, 20-23].

\section{Other ophthalmic manifestations}

Adnexal and anterior segment manifestations of rickettsiosis include bilateral or unilateral (Portal of entry of infection) conjunctivitis, conjunctival petechiae and subconjunctival hemorrhages, keratitis, nongranulomatous anterior uveitis, and iris nodule. Other reported ophthalmic findings include endophthalmitis and third and six cranial nerve palsies.

Diagnosis

Diagnosis of rickettsial infection usually based on clinical features and epidemiologic data is confirmed by positive indirect immunofluorescent antibody test results. Positive serologic criteria usually include either initial high antibody titer or a fourfold rise of the titer in the convalescent serum. Case confirmation with serology might take 2-3 weeks. Other laboratory tests, such as serologic testing using western blot or detection of rickettsiae in blood or tissue using polymerase chain reaction, may be useful in selected cases.

Ocular examination, revealing frequently abnormal, fairly typical findings is helpful in diagnosing a rickettsial disease, particularly in incomplete and atypical systemic presentation, while serologic testing is pending.

\section{Differential diagnosis}

The differential diagnosis of rickettsiosis includes numerous systemic infectious and noninfectious 
diseases manifesting with febrile illness, such as typhoid fever, measles, rubella, enteroviral infection, meningoccemia, disseminated gonococcal infection, secondary syphilis, leptospirosis, cat scratch disease, infectious mononuleosis, arbovirus infection, Kawasaki disease, Behçet's disease and other systemic vasculitic disorders, idiopathic thrombocytopenic purpura, and drug reaction.

Other important causes of retinitis and vasculitis such as toxoplasmosis and sarcoidosis should also be considered.

\section{Treatment}

Early treatment is critical to outcome and must be started on the basis of clinical diagnosis. Doxycycline (100 mg every $12 \mathrm{~h}$ for $7-10$ days) is the drug of choice for the treatment of rickettsial diseases. Antibiotic treatment may be terminated $48 \mathrm{~h}$ after the patient is afebrile. Other tetracyclines $(25-50 \mathrm{mg} / \mathrm{kg} / \mathrm{day})$, chloramphenicol (50-75 mg/kg/day) in four divided doses, and fluoroquninolones are also effective. Both tetracyclines and chloramphenicol have potential significant adverse effects, especially in children. Macrolides, including clarithromycin, azithromycin, and particularly josamycin can be used as alternative therapy in children and pregnant women [1].

Fluoroquinolones, because of their good ocular penetration, might be more effective than doxycycline in the treatment of intraocular rickettsial disease. Additional therapeutic agents may be required for ocular disease: topical antibiotic for conjunctivitis or keratitis, topical steroids and mydriatic drops for anterior uveitis, systemic steroids for severe ophthalmic involvement, such as extensive retinitis threatening the macula or optic disc, serous retinal detachment, macular edema, retinal vascular occlusion, severe vitritis, and optic neuropathy, and anticoagulant agents for retinal vascular occlusions. The role of antibiotic therapy, as well as that of oral steroids, on the course of posterior segment involvement, remains unknown. The effect of anticoagulants on the course of retinal occlusive complications is also unclear [18].

Prevention is the mainstay for control of rickettsial diseases: personal protection against tick bites in endemic areas (repellents, protective clothing, and avoidance of dogs, detection and removal of an attached tick), improvement of sanitary conditions including the control of rat reservoirs and of flea or lice vectors.

Evolution and prognosis

Although prognosis of systemic infection is good in most cases, rickettsioses may be severe and potentially lethal, and should be treated accordingly.

Ophthalmic manifestations of rickettsioses have a self-limited evolution in most patients, disappearing between the 3rd and 10th week after the first examination. All inner white retinal lesions clear without causing scarring. Retinal pigment epithelium (RPE) changes develop in eyes with resolved full-thickness white retinal lesions. Retinal neovascularization developed in one patient after resolution of retinitis 6 months after initial presentation [4] (Fig. 1C). Visual acuity returns to baseline in most patients. Persistent decreased vision may occur due to retinal changes secondary to macular edema or serous retinal detachment, retinal artery or vein occlusion, foveal chorioretinal scar, or optic neuropathy.

\section{West Nile virus infection}

\section{Epidemiology}

The West Nile virus (WNV), first isolated in 1937 in the West Nile district of Uganda, is an enveloped single-stranded RNA flavivirus. It is a member of the Japanese encephalitis virus serocomplex, which includes Japanese encephalitis virus, Saint Louis encephalitis virus, Murray Valley encephalitis virus, and Kunjin virus [24]. The virus is widely distributed in Africa, Europe, Australia, and Asia, and, since 1999, it has spread rapidly throughout the Western hemisphere, including the United States, Canada, Mexico, and the Caribbean and into parts of Central and South America [25]. West Nile virus infection is a zoonotic disease most often transmitted to human by an infected Culex mosquito vector with wild birds serving as its reservoir. The disease has been reported to occur anytime between July and December, with a peak onset in late summer. Other modes of transmission have recently been recognized, including blood transfusion, organ transplantation, transplacental transmission, laboratory transmission, and breast feeding [26]. 
Systemic disease

The incubation period of WNV ranges from 3 to 14 days. About $80 \%$ of human infections are apparently asymptomatic. Only approximately $20 \%$ of persons infected become symptomatic with a selflimited febrile illness in most cases. Symptoms of affected patients include high-grade fever, headache, myalgia, arthralgia, malaise, nausea, vomiting, skin rash, weakness, and pharyngitis. The acute illness is self-limiting, typically lasting less than a week.

Severe neurologic disease (meningoencephalitis), frequently associated with advanced age and diabetes, was initially reported to occur in $<1 \%$ of patients. However, over time, WNV infection has increased in severity [24-26].

\section{Ocular disease}

Since the first descriptions of ocular involvement secondary to WNV infection in 2002 and 2003, several ophthalmologic findings have been recognized, including chorioretinitis, anterior uveitis, retinal vasculitis, optic neuritis, and congenital chorioretinal scarring [26-44].

\section{Chorioretinitis}

A bilateral or rarely unilateral multifocal chorioretinitis, with typical clinical and fluorescein angiographic features, is the most common finding, occurring in almost $80 \%$ of patients with acute WNV infection associated with neurologic illness [31]. Diabetes mellitus appears to be a potential risk factor for developing multifocal chorioretinitis, with more than $20 \%$ of patients having diabetic retinopathy in association with multifocal chorioretinitis. Most patients have no ocular symptoms or present with mildly reduced vision. An associated mild to moderate vitreous inflammation is frequently observed. The chorioretinal lesions commonly develop early in the course of the disease, appearing to be active $(35 \%)$ or already inactive (65\%) at presentation [31]. Active chorioretinal lesions appear as circular, deep, creamy lesions on ophthalmoscopy, with early hypofluorescence and late staining on fluorescein angiography (Fig. 2). Inactive
Fig. 2 A-C Multifocal active chorioretinitis secondary to West Nile virus infection. A Diabetic 62-year-old woman with a 6-day history of fever, headache, vomiting, and weakness complained of mild redness and floaters in both eyes. Visual acuity was 20/20 in both eyes. A Redfree fundus photograph of the right eye shows superotemporal, inferotemporal and nasal linear clusterings of deep, creamy chorioretinal lesions (arrows) and associated faint intraretinal haemorrhages. Fluorescein angiography shows early hypofluorescence $(\mathbf{B})$ and late staining $(\mathbf{C})$ of the chorioretinal lesions
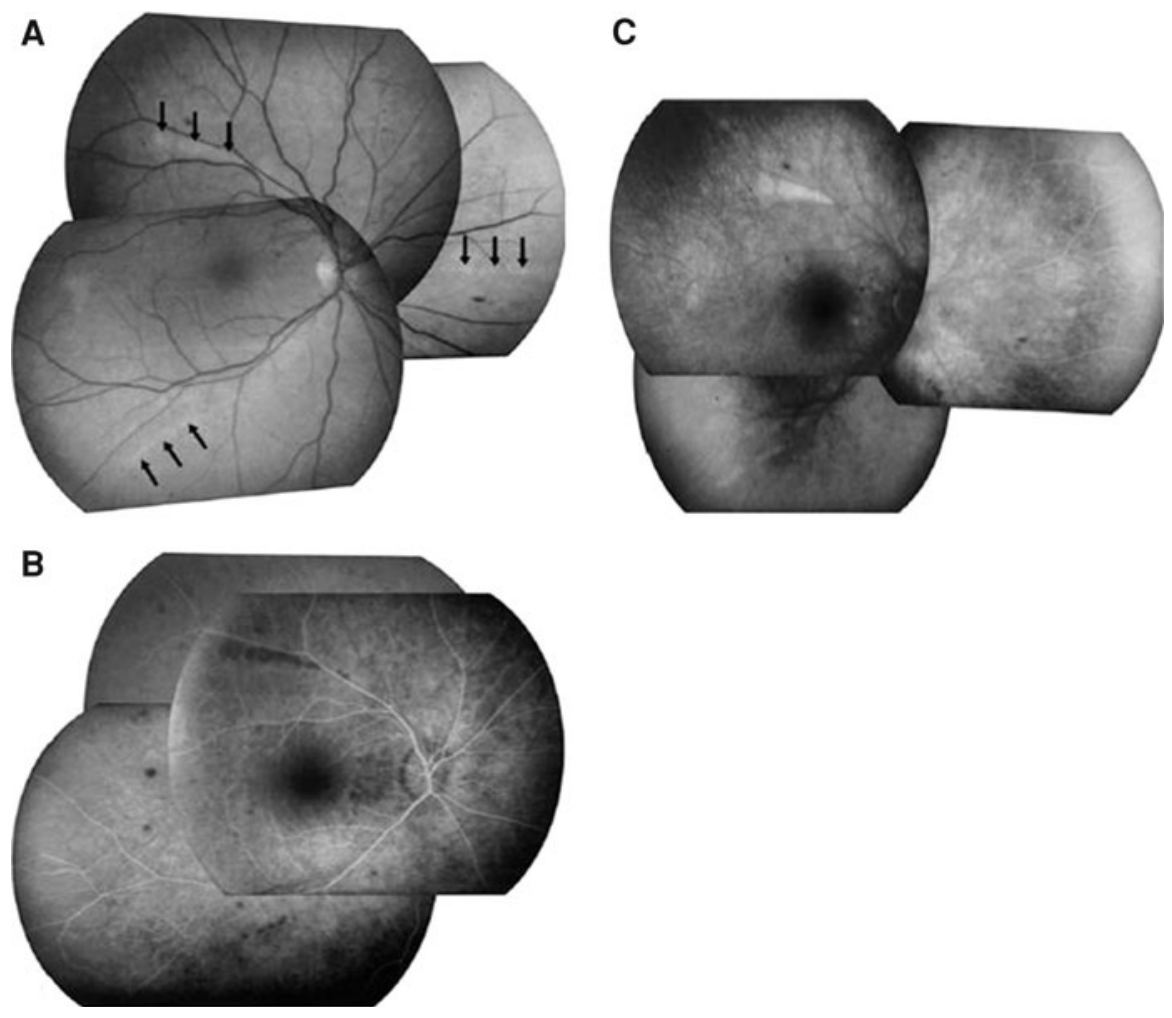
Fig. 3 Fundus photograph of the right eye (A) of a 58year-old diabetic man with a history of West Nile virus infection shows multiple partially atrophic, partially pigmented chorioretinal lesions. B Midphase fluorescein angiogram of the same eye shows more lesions that are observed clinically. C Late phase indocyanine green angiogram shows welldelineated hypofluorescent choroidal lesions, which are more numerous than those appreciated on fluorescein angiography or clinically
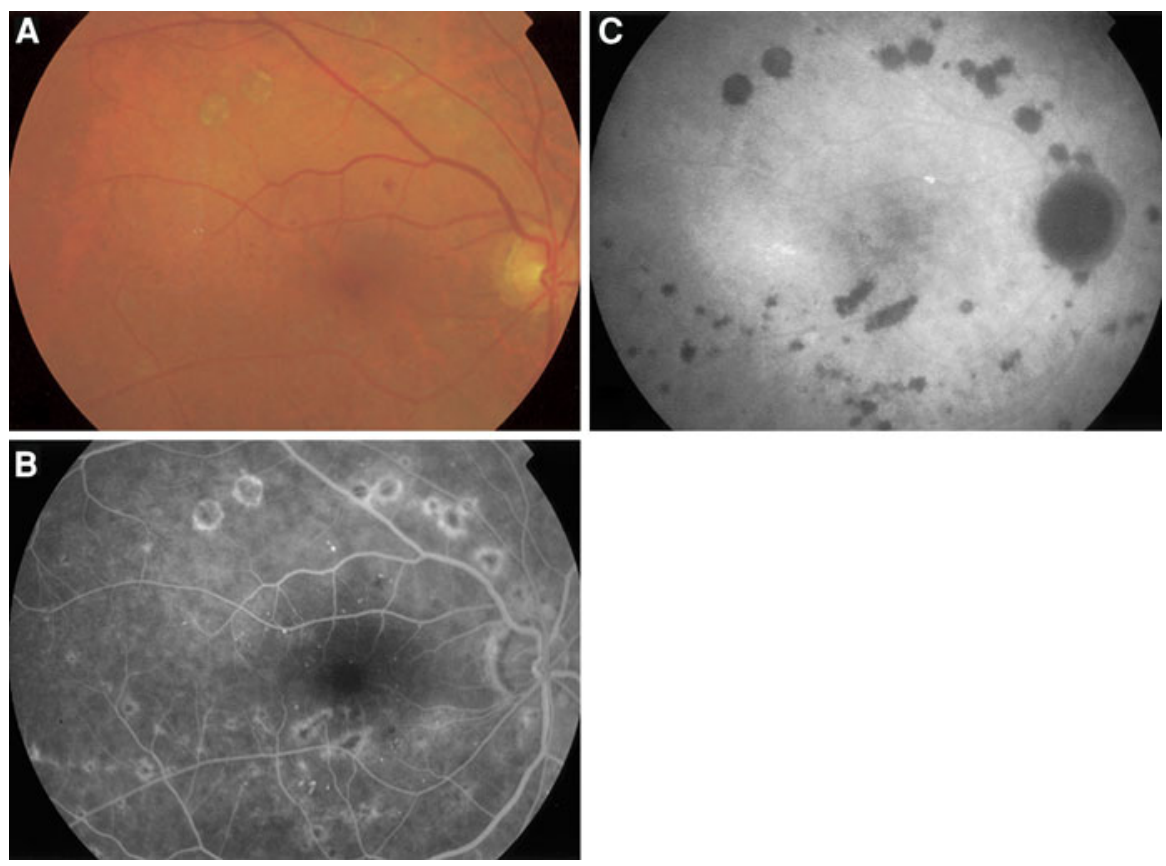

chorioretinal lesions are partially atrophic and partially pigmented with a "targetlike appearance": central hypofluorescence by blockage from pigment and peripheral hyperfluorescence (Fig. 3A, B). Some atrophic lesions are not pigmented. The lesions vary in number from $<20$ to more than 50 per eye. Chorioretinal lesions involve the midzone and/or periphery in almost all eyes. The posterior pole is involved in nearly $2 / 3$ of eyes. Lesion size range from 100 to $1,500 \mu \mathrm{m}$, with most of the lesions measuring 200-500 $\mu \mathrm{m}$. Linear clustering of chorioretinal lesions is a prominent feature, occurring in more than $80 \%$ of eyes with chorioretinitis (Fig. 4A). The streaks vary in number, from one to more than 3 per eye, and in length approximately from 2 to $15 \mathrm{~mm}$. They typically are oriented radially in the nasal and peripheral fundus or arranged in a curvilinear pattern in the temporal posterior fundus. The linear pattern of chorioretinitis appears to be related to the course of retinal nerve fibers, suggesting a contiguous spread of central nerve system disease (Fig. 4B) [45].

Indocyanine green angiography shows well-delineated hypofluorescent choroidal lesions, which are more numerous than those appreciated by fluorescein angiography or clinically (Fig. 3C) [43].

Diabetes was found to be a risk factor for WNVassociated chorioretinitis. It was also associated with more severe chorioretinal involvement [46]. A recent prospective, controlled case series study emphasized the value of the typical multifocal chorioretinitis as a specific marker of WNV infection, particularly in patients who present with meningoencephalitis [47].

\section{Other ophthalmic manifestations}

Although a typical multifocal chorioretinitis is the most common ocular manifestation of WNV infection, other findings can be observed. Anterior uveitis associated with vitritis in the absence of chorioretinitis has been reported [34]. Numerous retinal vascular changes can occur, including retinal hemorrhages, focal or diffuse vascular sheathing, vascular leakage, and occlusive vasculitis [26, 31, 36, 37]. One patient with WNV infection had peripheral, segmental wedge-shaped zones of atrophy and mottling of the RPE, which might be due to occlusion of ciliary artery [31]. West Nile Virus-associated optic nerve involvement may occur, including optic neuritis, optic disc swelling, and optic disc staining on fluorescein angiography [31, 38-41]. Other reported neuroophthalmic manifestations include ocular nerve palsy and nystagmus [31]. A case of congenital chorioretinal scarring secondary to intra-uterine transmission of WNV infection has been reported [42]. 
Fig. 4 A, B Midphase fluorescein angiogram (A) of the left eye of a diabetic 65 -year-old woman with a history of WNV infection shows multiple linear streaks, which follow the course of retinal nerve fibres $(\mathbf{B})$
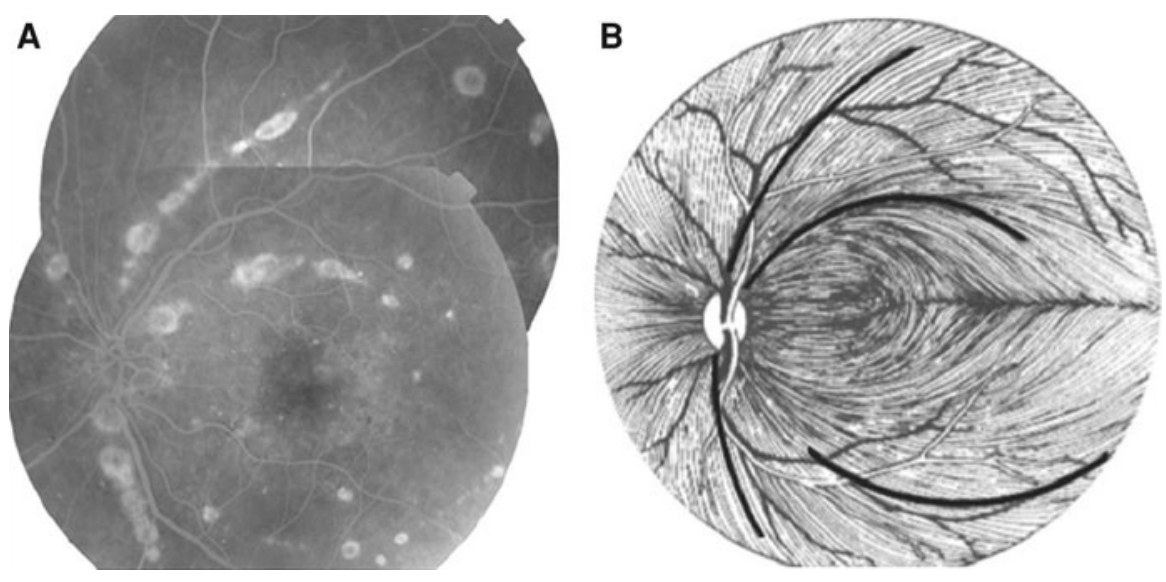

Diagnosis

Diagnosis of WNV infection requires a high index of suspicion and specific laboratory testing. The most common efficient diagnostic method is detection of WNV-specific IgM antibody in serum or cerebrospinal fluid using the antibody-capture enzyme-linked immunoabsorbent assay. Since IgM antibody does not cross the blood-brain barrier, its presence in the cerebrospinal fluid strongly suggests infection of the central nervous system. The plaque-reduction neutralization test can help distinguish false-positive results of MAC-ELISA or other assays as well as to help to distinguish serologic cross-reactions among the flaviviruses [24].

The unique pattern of multifocal chorioretinitis can help establish an early diagnosis of the disease while serologic testing is pending.

\section{Differential diagnosis}

The differential diagnosis of WNV systemic disease include other arthropod-borne viral encephalitides, enteroviral aseptic meningitis, Herpesvirus encephalitis, encephalopathy from systemic illnesses (Legionnaires Disease, rickettsiose, Epstein-Barr virus infectious mononucleosis, and systemic lupus erythematosus), epidural abcess, hypertensive encephalopathy, and drug-induced meningitis.

Many infectious and inflammatory conditions may present with chorioretinitis. The differential diagnosis includes syphilis, tuberculosis, histoplasmosis, sarcoidosis, and idiopathic multifocal chorioretinitis
[26]. West Nile Virus-associated chorioretinitis can be distinguished from these entities on the basis of history, systemic signs and symptoms, and particularly the unique pattern of chorioretinitis.

\section{Treatment}

There is, at present, no proven treatment for WNV infection. In cases of severe systemic disease, intensive supportive therapy is indicated, often involving hospitalization, intravenous fluids, respiratory support, prevention of secondary infections, and good nursing care.

Antiviral agents such as ribavirin and interferon were found to be active only in vitro [48, 49].

Several clinical studies, including an open-label trial of interferon $\alpha-2 b$ and a placebo-controlled trial using high-titer intravenous immunoglobulin, are ongoing [50].

Prevention is the mainstay of WNV infection control: measures to reduce the number of mosquitos (draining standing water, larvicides), personal protection (repellents, window screen, protective clothing). Vaccination, a long term solution, is still in the research phase $[26,50]$.

Specific ophthalmic treatment may be required: topical steroids for anterior uveitis, peripheral retinal photocoagulation for neovascularization due to occlusive vasculitis, pars plana vitrectomy for non-clearing vitreous hemorrhage or tractional retinal detachment, and intervention with laser, photodynamic therapy, or intravitreal injection of anti-VEGF for choroidal neovascularization [36]. 
Fig. 5 A Fundus

photograph of the right eye of a patient with Rift valley fever shows active retinitis in the macular region. Note the presence of retinal hemorrhages. B Four months later, an atrophic retinochoroidal scar has replaced the active lesion (Courtesy: E Abboud)
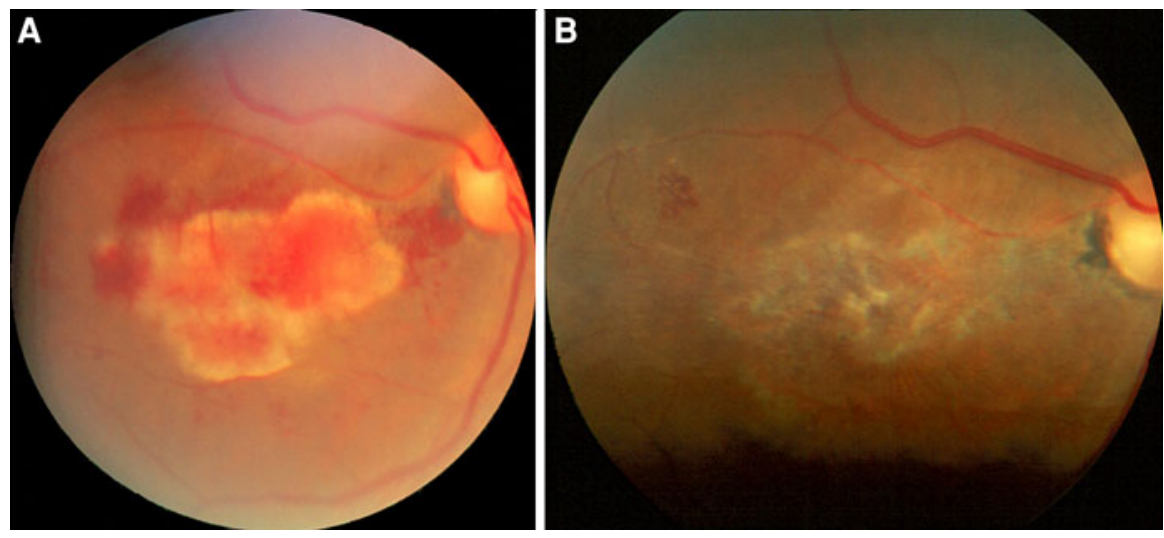

Evolution and prognosis

The outcome WNV systemic disease is good in most patients. However, severe cases may result in neurologic sequelae or death, especially in patients who are elderly or debilitated [24, 25].

Ocular involvement usually have a self-limited course. Active chorioretinal lesions at presentation evolved to the typical inactive stage. Some inactive lesions become more prominent on both ophthalmoscopy and fluorescein angiography. Visual acuity returns to baseline in most patients. However, persistent visual impairment may occur due to a foveal chorioretinal scar, choroidal neovascularization, and complications of occlusive retinal vasculitis, such as vitreous hemorrhage secondary to retinal neovascularization, severe ischemic maculopathy (Fig. 5), optic atrophy, or retrogeniculate damage $[26,35,36,38,39,43]$.

\section{Rift valley fever}

Epidemiology

Rift Valley fever (RVF) is an arthropod-borne viral disease caused by Bunyaviridae, primarily affecting domesticated cattle. It is transmitted to humans through a bite by infected mosquitoes or through direct contact with infected animals [51]. The disease was first described in the Rift Valley of Kenya in 1930 [52]. Since, several outbreaks have been reported in sub-Saharan and North Africa, and more recently in Arabian Peninsula.
Systemic disease

Human exposure to the virus is often occupational, either through handling infected livestock or their products or by breathing in aerosols released at slaughter. Mosquito bites and the consumption of raw milk have been documented as routes of exposure. The incubation period in humans is generally from 3 to 7 days, followed by one of three clinical syndromes.

The most common clinical syndrome is an uncomplicated, febrile, influenza like illness. The main symptoms are fever with biphasic temperature curve, headache, arthralgias, myalgias, and gastrointestinal disturbances [53]. The fever subsides in 12$36 \mathrm{~h}$, and the other symptoms are relieved within 4 days. Other clinical presentations include a hemorrhagic fever with liver involvement, thrombocytopenia, icterus and bleeding tendencies; and a neurologic involvement with encephalitis following a febrile episode with confusion and coma. Death is infrequent but there may be some residual damage.

\section{Ocular disease}

Ocular involvement has been reported to occur in 1$20 \%$ of RVF infections [52-58]. Al-Hazmi et al. [54] recently reported the largest series (30 hospitalized patients and 113 outpatients) of serologically proven RVF with ocular manifestations during an outbreak in Saudi Arabia. The mean interval between the onset of RVF and visual symptoms ranged from 4 to 15 days. Macular or paramacular retinitis was identified in all the affected eyes at the time of initial assessment 
Fig. 6 A, B Retinitis secondary to Rift Valley fever infection. A Fundus photograph of the right eye with large active geographic retinitis. Note the healthy disc. B Six months later, severe sheathing and atrophy of the optic disc are easily seen (Courtesy: E Abboud)
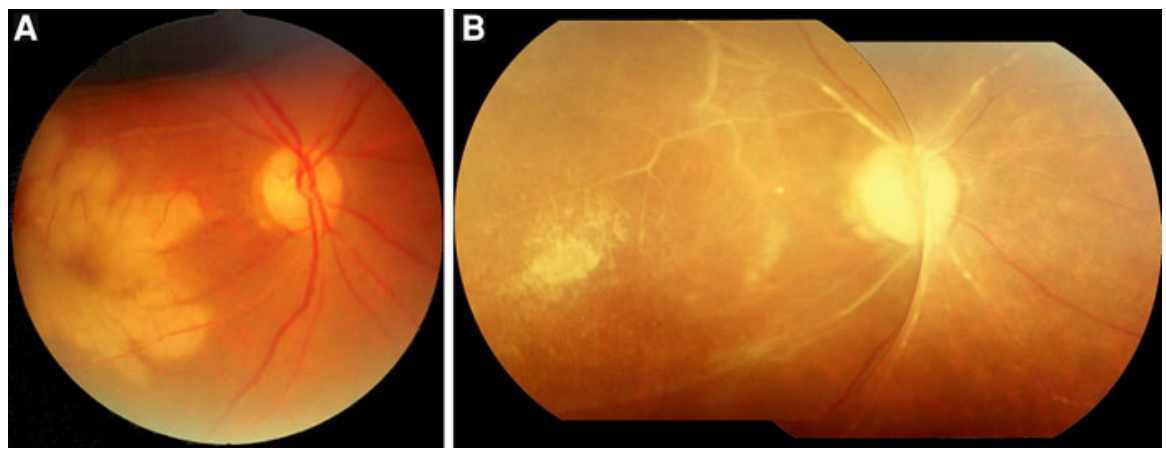

(Fig. 5A, 6A). Other lesions included retinal hemorrhages $(40 \%)$, vitreous reactions $(26 \%)$, optic disc edema (15\%), and retinal vasculitis (7\%). Anterior uveitis was present in $31 \%$ of outpatients. Fluorescein angiography of the retinitis showed early hypofluorescence with late staining of retinal lesions and blood vessels. Symptoms resolved spontaneously within 2-3 weeks from the onset of systemic symptoms and did not result in complications such as glaucoma, posterior synechiae, or cataract. Initial visual acuity was $<20 / 200$ in $80 \%$ of eyes in the outpatient group. Vision remained the same or deteriorated in $87 \%$ of eyes. Evaluation at the last follow-up showed macular $(60 \%)$ or paramacular (9\%) scarring, vascular occlusion (23\%), and optic atrophy (20\%) in the outpatient group (Figs. 5B, 6B).

\section{Diagnosis}

Once an outbreak is recognized and early cases are proven, it becomes much easier to diagnose further cases of RVF. The most popular method of laboratory diagnosis uses serology to detect antibodies, either IgM antibodies in a single serum sample, or by detecting a rising titre of $\mathrm{IgG}$ antibody in acute and convalescent serum samples [59]. In patients with encephalitis, cerebrospinal fluid may be tested for locally produced IgM. With the presence of equipped virological laboratories, RVF virus can be isolated from blood in the acute phase of illness. Finally, PCR detects the viral nucleic acid sequence of the RVF virus both in serum and tissue [60].

\section{Differential diagnosis}

The differential diagnosis for RVF retinitis includes other viral entities such as measles, rubella, influenza, dengue fever, and West Nile virus infection. These diseases can be differentiated from RVF by clinical history and serologic testing. Other hemorrhagic fever viruses have been reported to have ocular involvement such as Hantaan virus, Puumala, Marburg, and Ebola viruses [61].

Some bacterial infections have been reported to cause retinitis. These mainly include rickettsial infection, Lyme disease, and cat scratch disease. These diseases can be ruled out with serologic testing.

\section{Treatment}

Treatment is entirely supportive: for mild to moderate cases of RVF simple analgesia and fluids can be administered. For patients who develop severe disease, including encephalitis, and hemorrhage, early recognition and aggressive critical care, including assisted ventilation and blood product transfusion is essential, for any hope of survival [62].

Intensified mosquito control methods must be implemented in areas of epizootic and human RVF activity. An increased awareness of RVF among both residents and visitors to endemic areas is paramount to the future control and prevention of outbreaks. Education regarding modes of disease transmission and necessary precautions, especially protection against mosquito bites is vital [63].

\section{Evolution and prognosis}

Most cases of human RVF manifest as a mild selflimited influenza like illness [62]. However, ocular involvement is frequently associated with permanent visual loss resulting from macular and paramacular scarring, vascular occlusion, and optic atrophy. 


\section{Dengue fever}

Epidemiology and systemic disease

Dengue fever is the most common mosquito-borne viral disease in humans. It is caused by the dengue virus, a Flavivirus, of which there are four serotypes, and is transmitted by the Aedes aegypti mosquito. It is considered to be one of the most important arthropod borne disease in the tropical and subtropical regions, being endemic in more than 100 countries. It afflicts 100 million people annually thereby putting 2.5 billion people at risk worldwide [64].

Dengue fever is endemic in Singapore but the number of cases has risen dramatically in the last few years [65]. In addition to fever, dengue fever also causes headaches, myalgia and thrombocytopenia, resulting in bleeding manifestations such as a purpuric rash. Hypotension may also occur in the Dengue Shock Syndrome which carries a high mortality rate [64].

More recently, dengue fever has also been found to affect the eyes, with resultant loss of vision [66-71].

Ocular disease

Ocular involvement in dengue fever has recently been reported from Singapore, Thailand, Taiwan, India, Mexico and Brazil [66-76]. In a cross-sectional observational study conducted in Singapore in 2005 during a dengue epidemic [77], we found that the prevalence of dengue maculopathy among patients hospitalized for dengue fever was $10 \%$.

These patients tend to be young, with an average age of 29 years, ranging from 11 to 61 years [72]. There is no sex or racial predilection $[72,77]$.

\section{Subconjunctival hemorrhage}

The commonest ocular involvement reported in an East Indian population was a petechial type of subconjunctival hemorrhage (37\%), which was associated with a platelet count of $<50,000 / \mu 1$ [73].

\section{Dengue maculopathy}

This occurs as a result of involvement of the retinal and/or choroidal vessels, with a predilection for the macula area. Anterior segment involvement is usually mild and may be easily missed. The ocular symptoms may range from mild blurring of vision to catastrophic and severe blindness and they usually occur within a month of the onset of the dengue infection.

The fundal manifestations typically occur one week after the onset of fever, just as the fever has settled and the platelet count is recovering [69, 71]. The patients may present with a sudden decrease in vision $(87 \%)$, a central scotoma $(63 \%)$ or floaters (1\%) [72]. The involvement is bilateral in $73 \%$ but tends to be asymmetrical [72]. The mean initial bestcorrected visual acuity was 20/45 [72]. The main fundal findings [72] were: retinal haemorrhage $(45 \%)$ (Fig. 7), venular sheathing (Figs. 7, 8) $(45 \%)$ yellow subretinal dots (28\%), RPE mottling (17\%), round foveal swelling [foveolitis] (16\%) (Fig. 9), disc hyperemia (14\%), disc edema (11\%), and arteriolar sheathing (4\%). There may also be cells in the anterior chamber (17\%) and vitreous (11\%).

Dengue maculopathy involves both the retinal as well as the choroidal circulation, hence fluorescein and indocyanine green angiography) are important modalities in the assessment of its severity, as some of the changes may not be evident clinically and may therefore be missed [72].

Fluorescein Angiography (FA): The main FA findings [72] include: blocked fluorescence (33\%), venular occlusion (25\%), venular leakage (13\%), knobby capillary hyperfluorescence (13\%), RPE hyperfluorescence $(10 \%)$, venular leakage with occlusion $(5 \%)$, arteriolar leakage (3\%), RPE window defect $(3 \%)$, arteriolar occlusion $(2 \%)$, capillary nonperfusion (2\%) (Figs. 7, 8).

Interestingly, in $3 \%$ of eyes, fundal fluorescein angiography (FFA) is unremarkable despite clinically observed venous sheathing on fundus examination [72]. When the maculopathy involves larger retinal vessels, regardless of whether they are inflammatory or occlusive in nature, the visual acuity and field loss tends to be greater [72]. Furthermore, eyes with occlusive vascular involvement tend to have residual scotomas, corresponding to depressed multifocal ERG recordings [78].

Indocyanine Green Angiography (ICG): Yellow subretinal dots appear as early RPE hyperfluorescence on FFA, but these changes are seen in only $15 \%$ of the cases. In comparison, ICG showed hypofluorescent spots during the mid to late phase, corresponding to these yellow dots as well as 

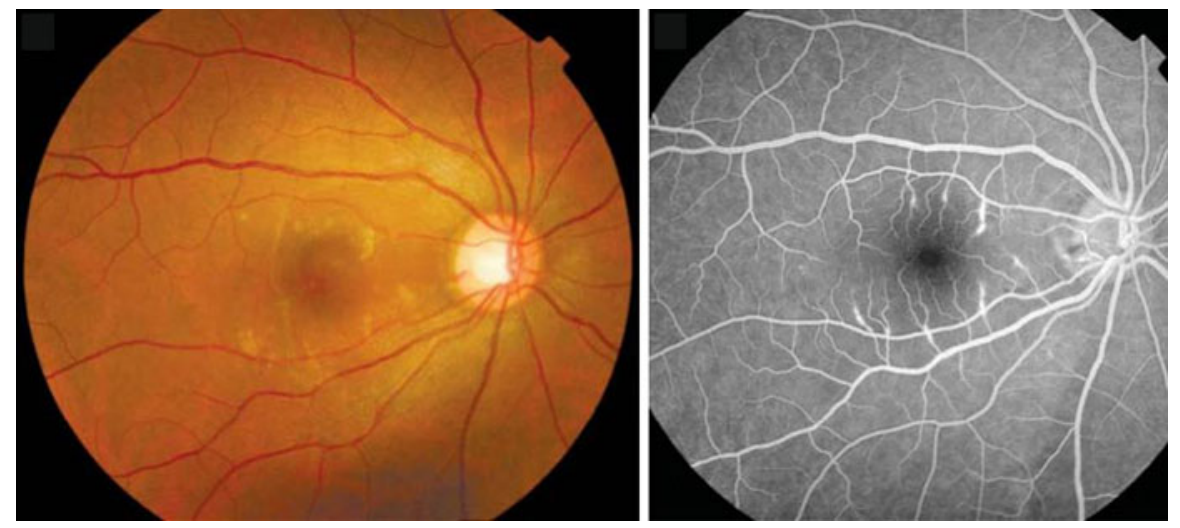

Fig. 7 Fundal photographs and fluorescein angiogram showing dengue maculopathy manifesting as mild right retinal vasculitis. This 34-year-old Chinese female with dengue hemorrhagic fever presented with blurred vision in the right eye, occurring 7 days after onset of dengue fever. Her Snellen

additional spots in areas without clinically evident dots in $29 \%$ of cases. The angiogram findings suggest that the yellow subretinal dots involve the choriocapillaries and/or RPE. These lesions resolve clinically without residual visual loss [72].

Large choroidal vasculopathy with hyperfluorescence and leakage is also seen on ICG (31\%) and is associated with mild reversible visual disability [72].

Optical coherence tomogram (OCT) is indispensable in eyes with decreased visual acuity but no apparent lesions can be observed on angiography. Foveolitis, clinically seen as a well-circumscribed pale yellowish lesion at the centre of the fovea is best imaged with the OCT, as FFA only rarely may demonstrate early foveal hyperfluorescence. OCT is able to image a corresponding area of focal outer neurosensory retina-RPE thickening at the foveal center (Fig. 9). It is also useful for monitoring clinical progress [72].

OCT is also useful for assessing the severity and monitoring the progress of neurosensory retinal detachment (Fig. 8) in 15\% of eyes with retinal vascular leakage. Macular cystic spaces were starkly absent in macular edema associated with dengue maculopathy [72].

\section{Pathophysiology}

The pathophysiologic mechanism of dengue maculopathy is still unclear. The average onset of ocular symptoms from the onset of illness is about 7 days visual acuity in the right eye was 6/60. Retinal vasculitis involving predominantly the macular venules is seen clinically as sheathing along the vessels (Left). The fluorescein angiogram shows mild dye leakage of some but not all of the clinically involved vessels (Right)

$[69,71,72,77]$. This delay as well as the lower the serum complement $\mathrm{C} 3$ levels in patients with maculopathy as compared to those without maculopathy supports an immune-mediated mechanism rather than direct viral infection of the eye [72, 77].

\section{Diagnosis}

The diagnosis of dengue fever is based on the typical clinical presentation and a positive dengue $\operatorname{IgM}$ serology. The diagnosis of dengue maculopathy is based on clinical features as well as the imaging studies described below.

\section{Treatment}

It is unclear if treatment is beneficial nor what is the optimal modality of treatment, as the disease may be self-limiting and there have been no prospective randomized trials on therapy to date. Immunosuppression with topical, periocular, oral, intravenous steroids and immune globulins has been attempted with variable success [72].

\section{Chikungunya}

Chikungunya virus is an arthropod borne Alphavirus in the family Togaviridae [78]. It is responsible for the recent explosive epidemic in Indian Ocean region 
Fig. 8 Fundal photographs, fluorescein angiogram and OCT showing dengue maculopathy manifesting as severe retinal vasculitis with serous retinal detachment in both eyes. This 33-year-old Chinese female presented with sudden loss of vision 1 week after the onset of dengue hemorrhagic fever. Her Snellen visual acuities were $6 / 120$ bilaterally. Fundal examination showed severe macular hemorrhages, macular vasculitis with sheathing of predominantly the venules (Top left, right). The fundal fluorescein angiogram demonstrates prominent vascular leakage (Middle left, right). OCT shows the presence of severe neurosensory retinal detachment, accounting for the poor vision (Bottom left, right)
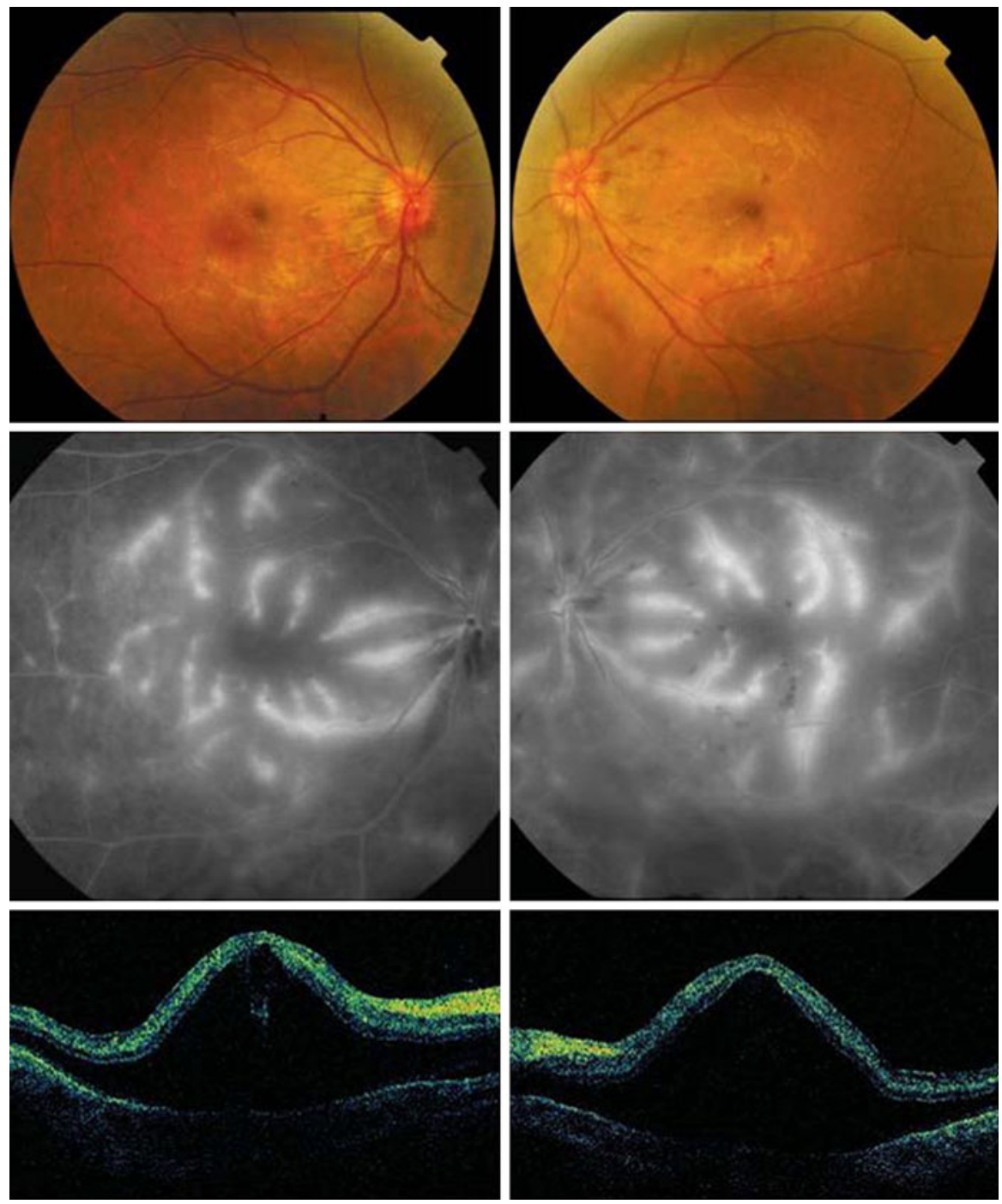

$[79,80]$. This virus has three distinct genotypes, the East African, West African and Asian, maintained in monkeys and wildlife populations. Epidemics are sustained by human-mosquito-human transmission by several mosquito species including Aedes aegypti and A. albopictus. The incubation period is $2-5$ days, disease may manifest about $48 \mathrm{~h}$ after mosquito bite [78]. Chikungunya is usually a self-limiting febrile illness lasting for few days to weeks; most of the patients recover without consequences. However the current outbreak seems to be more severe with increased morbidity and even significant mortalities [79-81]. This review highlights all systemic and ocular clinical manifestations of the disease which were not seen in previous outbreaks.

\section{Epidemiology}

Chikungunya virus was first isolated from the blood of a febrile patient in Tanzania in 1953. It is endemic in parts of west, central and southern Africa and few areas of Asia. Several outbreaks have been reported between 1957 and 1974, an explosive emergence of the disease occurred in island of Réunion in 2005 [82]. This outbreak is the most severe and one of the biggest outbreaks which has affected millions of the people in several islands in the Indian Ocean [82-84]. The disease then spread to Seychelles, Madagascar, Comoro Islands, Mauritius, and Mayotte subsequently to Sri Lanka, Maldives, India, Malaysia and Indonesia [79, 81, 82, 85-87]. Previous Indian outbreaks were caused by the 
Fig. 9 Fundal photograph, fluorescein and indocyanine green angiogram, and OCT showing dengue foveolitis in the left eye. This 27-yearold Chinese male developed blurred vision in both eyes 6 days after onset of dengue hemorrhagic fever. His

Snellen visual acuities were right counting fingers and left $6 / 120$. Fundal photograph of the left eye showed an elevated orange spot at the fovea (Top left). The fluorescein and indocyanine green angiograms were unremarkable (Top right, bottom left). The OCT demonstrated a focal thickening of the outer neurosensory retina-retinal pigment epithelial layer (Bottom right). The right eye had similar findings in addition to scattered macular hemorrhages (not shown)
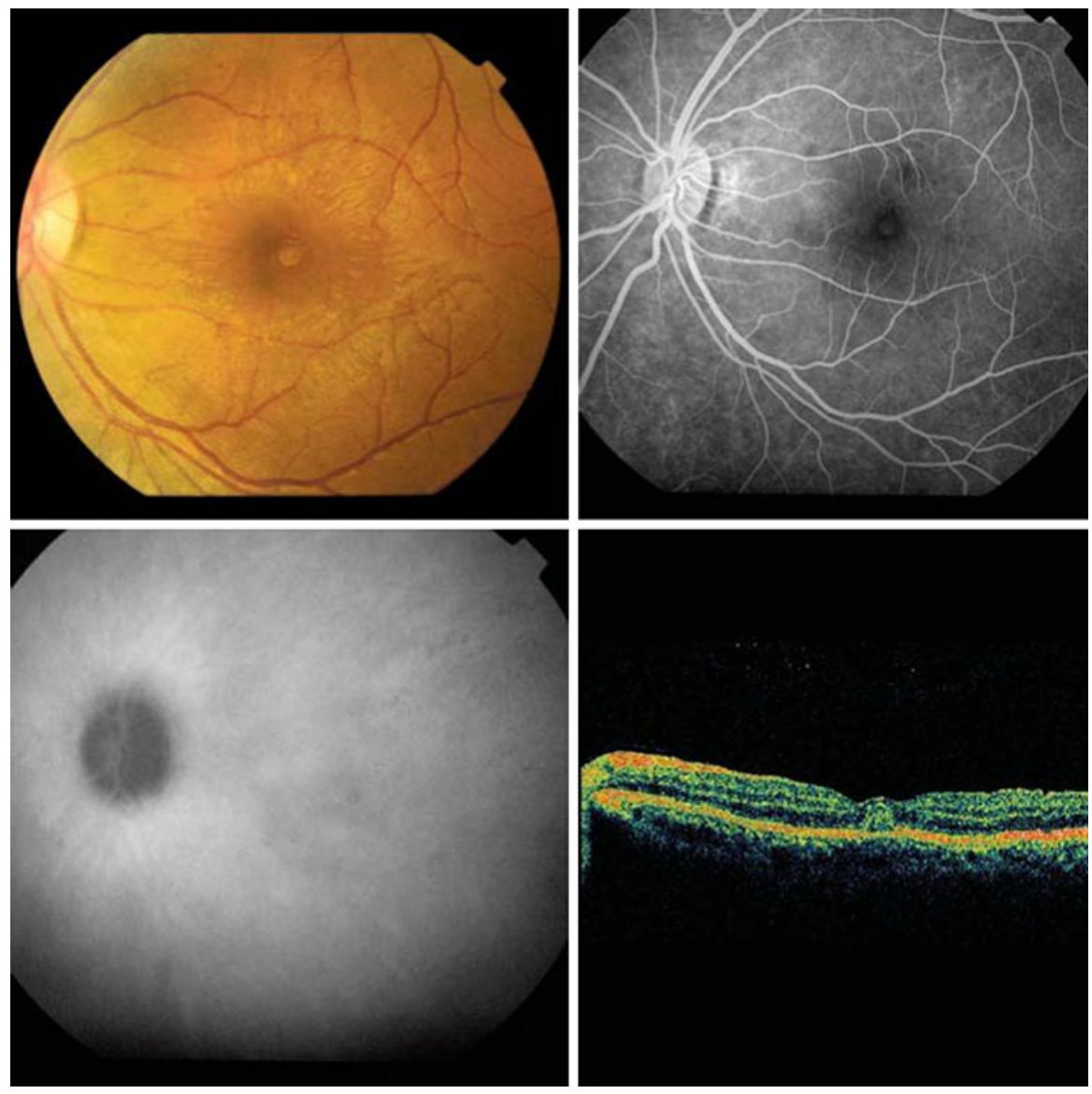

Asian genotypes, while the 2006 epidemic is attributed to the East African genotype [86, 87]. In 2007 NorthEastern Italy reported new cases [88]. Travelers returning from outbreak areas to Europe, Canada, the Caribbean and South America, United States, and Australia were found to suffer from Chikungunya fever [89-91]. Schuffenecker reported unique viral mutation, an emergence of a new genotype with an A226 V in the membrane fusion glycoprotein E1 which may be responsible for the enhanced adaptation in the vector [92]. Explosive nature of Chikungunya in the recent outbreak may also be associated this viral mutation, absence of herd immunity, lack of vector control, and globalization of travel [91-94].

Systemic disease

Chikungunya fever may manifest as acute fever with headache, fatigue, myalgia, diffuse maculo papular rash, bleeding from the nose or gums, peripheral edema, and joint pain [82-85, 90, 91]. The main clinical feature is a dramatic reduction in movement even to carry out routine daily activities due to impaired strength and pain in hands and legs. Prolonged fatigue, pronounced lethargy and depression last for several weeks [90]. Asymptomatic infections do occur but the incidence is not known [89]. The recent outbreak added neurological signs, vision threatening ocular complications, acute hepatic failure, multi organ failure and mother-to-child transmission [79, 81-85, 93].

The name, Chikungunya origins from the posture of the patients in Makonde language of southeastern Tanzania, which means to become contorted. They characteristically lie still in the attitude of flexion because of severe joint pains [85]. Joint pains are typically polyarticular and migratory, most severe in the morning [95-97]. Three different types of rheumatic manifestations may coexist in same patient including finger and toe polyarthritis, severe 
tenosynovitis of wrists, hands, and ankles [90]; and exacerbation of mechanic pain in previously injured joints [95-97]. In some patients, an invalidating polyarthralgia may persist for months or years [98]. Radiological findings, and biological markers of inflammation may remain normal [95].

When pregnant women in Réunion had acute chikungunya infection within $48 \mathrm{~h}$ before delivery, neonates presented with an abrupt onset of fever, flushing of the skin, maculopapular rash, conjunctival congestion, pharyngitis, upper respiratory tract disease and meningoencephalitis within 5 days of birth [83, 93]. Facial edema, gingivorrhagia, bullous rash, pronounced sloughing, and localised petechiae seem to be frequent in children. Chikungunya virus may be found by PCR in blister fluid [93]. Disease in older children behave like adult patients with acute fever, headache, myalgia, and polyarthralgia [98].

Neurologic manifestations of Chikungunya virus infection was very rare previously [99], sero positive meningoencephalitis have been reported both in adults and children in the present epidemic, some patients also had viral genome in the cerebrospinal fluid [100, 101]. As seen in several arboviruses, Guillain-Barre' syndrome has been seen in serologically proven Chikungunya virus patients [99]. Other neurological signs include bilateral external ophthalmoplegia, upper motor neuron facial palsy, hemiparesis, incongruous homonymous hemianopias suggestive of optic tract lesions [102].

\section{Ocular disease}

So far Chikungunya was known to cause minor ocular signs such as, photophobia, conjunctivitis and retro orbital pain [78]. However more recent reports reveal both mild as well as vision threatening ocular complications [102-106]. Ocular symptoms usually occur after a latent period of a month to year; however few concurrent presentations have also been reported $[102,105]$. It is either unilateral or bilateral, affecting both the genders in all age groups. Two distinct presentations are seen in this infectious uveitis including anterior and posterior uveitis [102-106].

\section{Anterior uveitis}

Patients present with symptomatic uveitis including redness, pain, photophobia, blurred vision, and

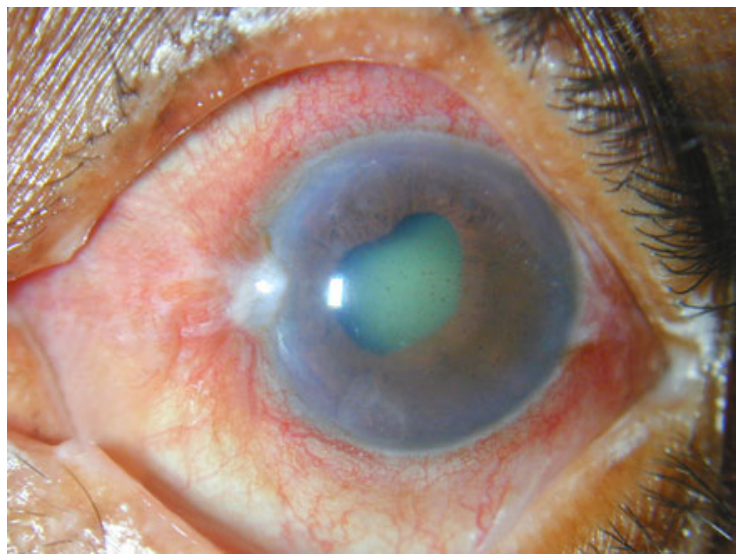

Fig. 10 Anterior segment photograph of left eye of a patient with Chikungunya infection shows diffuse pigmented keratic precipitates and posterior synechiae

floaters. A mild granulomatous or nongranulomatous anterior uveitis, pigmented diffuse keratitic precipitates on the central or over the entire corneal endothelium and stromal edema may be seen on slit lamp examination (Fig. 10) [103-105]. Posterior synechiae is not common. These eyes develop uveitis-induced raised intraocular pressure with open angles even before steroid use. Anterior uveitis closely mimic herpitic viral keratouveitis, however bilateral involvement is uncommon in herpetic uveitis. Significant iris pigment release in the anterior segment, past history of fever with and joint pain along with positive serologic results can differentiate this from herpitic disease. Visual prognosis in Chikungunya anterior uveitis is good [103-105].

\section{Posterior uveitis}

Patients may present with history of loss of vision, color vision defect, central or centrocecal scotoma and peripheral field defects [102-106]. Patients with posterior uveitis may have normal anterior segment and intraocular pressure is normal. Posterior pole or macular retinochoroiditis appear relatively more specific and carries very poor visual prognosis (Fig. 11) [103, 104, 106]. Chikungunya retinitis is similar to herpetic retinitis however markedly less vitreous reaction and confluent posterior pole retinitis can differentiate Chikungunya from the acute retinal necrosis which is characterized by intense vitritis and 


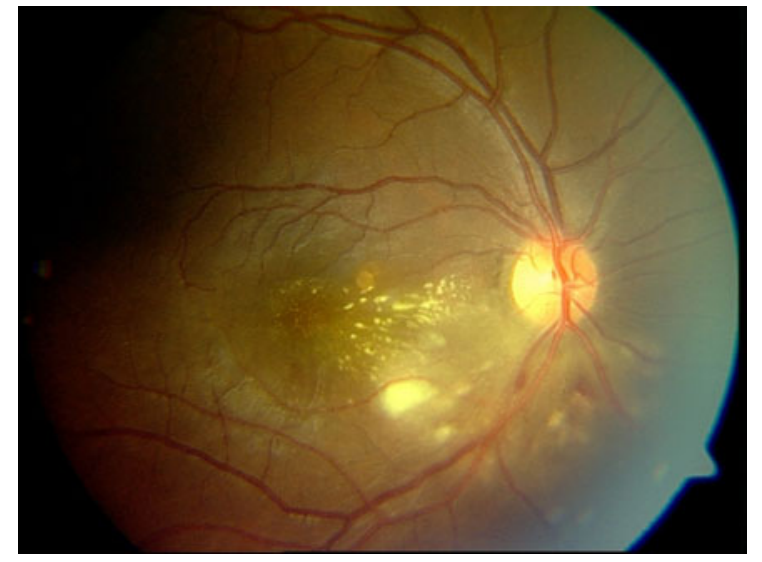

Fig. 11 Fundus photograph of the right eye of a patient with Chikungunya showing neuroretinitis, multifocal retinitis and temporal optic disc pallor

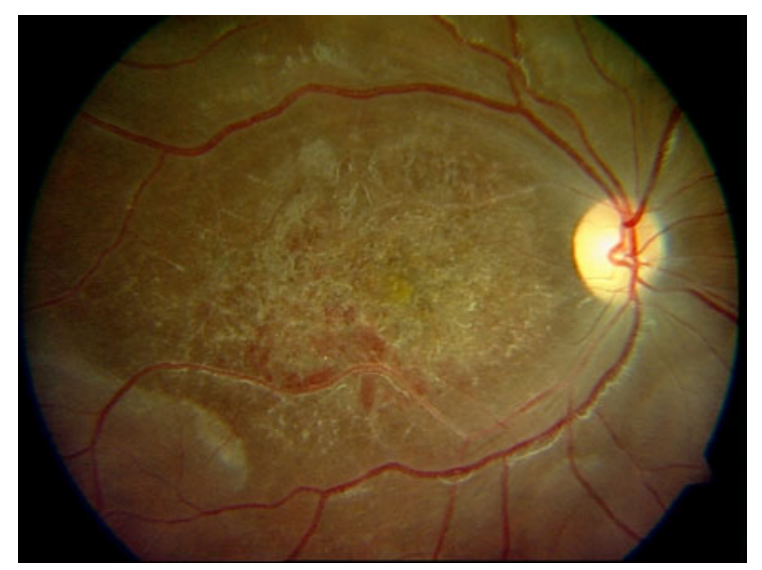

Fig. 12 Fundus photograph of the right eye of a patient with Chikungunya showing an extensive atrophic retinochoroidal scar and vascular sheathing following resolution of retinitis. Note the presence of temporal disc pallor

peripheral multifocal or disseminated retinitis [103, 104]. Other posterior segment signs include optic neuritis, neuroretinitis (Fig. 12) and retrobulbar neuritis [102, 103].

To summarise, the individuals with anterior uveitis with pigmented keratic precipitates or confluent posterior pole retinochoroiditis or optic neuritis or neuroretinitis and a history of fever with arthralgia who live in or come from endemic area for Chikungunya virus may have this entity included in the differential diagnosis.

\section{Differential diagnosis}

Chikungunya is clinically very similar to dengue fever, West Nile fever, urban yellow fever and O'nyong-nyong fever. Though Dengue and Chikungunya are transmitted by the same vector, the incubation periods are dramatically different. In the ideal laboratory condition the average incubation period for dengue ranges from 8 to 14 days, while for Chikungunya it is 2-5 days [87]. Abrupt onset and shorter duration of fever with arthralgia are frequent in Chikungunya, hemorrhagic manifestations are uncommon and as a rule shock is not observed [85, 107, 108]. Decreased platelet count, severe haemorrhage and shock are characteristic of dengue, rashes occur in both the diseases but are more common in dengue. However confirmatory diagnosis of Chikungunya fever from dengue or O'nyong-nyong can be made only by the laboratory investigation.

\section{Laboratory tests}

Complete haemogram reveals leucopoenia, lymphocytosis, mild thrombocytopenia, an elevated erythrocyte sedimentation rate and a positive C-reactive protein in acute cases $[78,87,109]$. Three specific laboratory tests are, virus isolation, serological tests and molecular techniques [110-116]. Virus isolation and RT-PCR are useful during the initial viraemic phase (day 0-day 7) while serological methods are useful after 10 days of infection. However all three diagnostic modalities are not available in most of the places. The major challenge is to develop and standardize the diagnostic kits for regional hospitals to perform the diagnostic tests [87].

\section{Virus isolation}

Chikungunya virus produces cytopathic effects in a variety of cell lines including BHK-21, HeLa and Vero cells. The cytopathic effects must be confirmed by Chikungunya specific antiserum and the results will be available in 1-2 weeks [110-112].

\section{Serological diagnosis}

Serologic diagnosis can be made by demonstration of fourfold increase in antibody in acute and convalescent sera or demonstrating IgM antibodies specific for 
Chikungunya virus $[78,110,111]$. A commonly used test is the $\operatorname{IgM}$ Antibody capture enzyme-linked immunosorbent assay.

\section{Molecular techniques}

Reverse transcriptase Polymerase chain reaction (RTPCR) technique is used for specific detection of the virus amplifying fragment of E-2 gene [114]. Combined detection and genotyping of Chikungunya has been developed targeting nsP1 and E1 genes [115]. More recently, specific and sensitive one-step TaqMan RT-PCR assay is available as a tool for diagnosis and rapid indicator of active infection by quantifying viral load in clinical samples and cell culture supernatant [116].

\section{Treatment}

\section{Systemic treatment}

Specific antiviral drug is not available; treatment is mainly symptomatic including rest, non steroidal anti inflammatory drugs and paracetamol. Patients with dehydration, who cannot take oral fluids may need intravenous rehydration. Dramatic improvement is observed with corticosteroids, especially in the presence of refractory arthritis, tenosynovitis, nerve entrapment syndromes, or Raynaud phenomenon [97].

\section{Ocular treatment}

As there is no specific anti viral drug, only topical steroid eye drops are given in case of simple anterior uveitis. Timolol maleate $0.5 \%$ eye drops twice daily and oral Acetazolamide, $250 \mathrm{mg}$ twice daily for 3 days are added with topical steroids when the patients come with uveitic glaucoma. Even though there is no evidence in the literature to support on efficacy of acyclovir or other antiviral agents against Chikungunya, some investigators treat confluent retinitis with intravenous/oral acyclovir and oral prednisolone [102-106].

\section{Prognosis}

Chikungunya is thought to confer life-long immunity [89]. In general, the disease is benign and self-limiting.
Visual prognosis in Chikungunya anterior uveitis is better than in the posterior form.

\section{References}

1. Parola P, Raoult D (1998) Rickettsioses éruptives EMC (Elsevier Paris) Maladies Infect 8-037-I-20: 24

2. Mc Dade JE (1998) Rickettsial diseases. In: Hausler WJ, Sussman M (eds) Topley and Wilson's microbiology and microbial infections, 9th edn, vol 3. Arnold, London, pp 995-1011

3. Alio J, Ruiz-Beltran R, Herrero-Herrero JI, Hernandez E (1987) Retinal manifestations of Mediterranean spotted fever. Ophthalmologica 195:31-37

4. Khairallah M, Ladjimi A, Chakroun M, Messaoud R, Ben Yahia S, Zaouali S, Ben Romdhane F, Bouzouaia N (2004) Posterior segment manifestations of Rickettsia conorii infection. Ophthalmology 111(3):529-534

5. Raab EL, Leopold IH, Hodes HL (1969) Retinopathy in Rocky Mountain spotted fever. Am J Ophthalmol 68: 42-46

6. Presley GD (1969) Fundus changes in Rocky Mountain spotted fever. Am J Ophthalmol 67:263-267

7. Smith TW, Burton TC (1977) The retinal manifestations of Rocky Mountain spotted fever. Am J Ophthalmol 84:259-262

8. Duffey RJ, Hammer ME (1987) The ocular manifestations of Rocky Mountain spotted fever. Ann Ophthalmol 19:301-306

9. Lukas JR, Egger S, Parschalk B, Stur M (1998) Bilateral small retinal infiltrates during rickettsial infection. Br J Ophthalmol 82:1215-1218

10. Hudson HL, Thach AB, Lopez PF (1997) Retinal manifestations of acute murine typhus. Int Ophthalmol 21:121-126

11. Khairallah M, Ben Yahia S, Toumi A et al (2009) Ocular manifestations associated with murine typhus. $\mathrm{Br} \mathrm{J}$ Ophthalmol

12. Esgin H, Akata F (2001) Bilateral multiple retinal hyperfluorescent dots in a presumed Rickettsia conorii infection. Retina 21:535-537

13. Lu TM, Kuo BI, Chung YM, Liu CY (1997) Murine typhus presenting with multiple white dots in the retina. Scand J Infect Dis 296:632-633

14. Paufique L, Bonnet M (1964) Thromboses vasculaires rétiniennes et rickettsioses. Bull Soc Ophtalmol Fr 64:410-415

15. Verdot S, Estavoyer JM, Prost F, Montard M (1986) Atteinte oculaire en phase aiguë de fièvre boutonneuse méditerranéenne. Bull Soc Ophtalmol Fr 86:429-431

16. Adan A, Lopez-Soto A, Moser C, Coca A (1998) Use of steroids and heparin to treat retinal arterial occlusion in Mediterranean spotted fever. J Infect Dis 158:1139-1140

17. Nagaki Y, Hayasaka S, Kadoi C, Matsumoto M, Sakagami T (2001) Branch retinal vein occlusion in the right eye and retinal hemorrhage in the left eye in a patient 
with classic Tsutsugamushi disease. Jpn J Ophthalmol 45:108-110

18. Vaphiades MS (2003) Rocky Mountain Spotted Fever as a cause of macular star figure. J Neuroophthalmol 23:276-278

19. Mendivil A, Cuartero V (1998) Endogenous endophthalmitis caused by Rickettsia conorii. Acta Ophthalmol Scand 76:121-122

20. Bronner A, Payeur G (1973) Hemorrhagic papillitis and rickettsiosis. Bull Soc Ophtalmol Fr 73:355-358

21. Castanet J, Costet C (1988) Neuropathie optique au cours d'une fièvre boutonneuse méditerranéenne. Presse Med 17:439-440

22. Granel B, Serratrice J, Rey J, Conrath J, Disdier P, Weiller PJ (2001) Impaired visual acuity in Mediterranean boutonneuse fever. Presse Med 30:859

23. Khairallah M, Zaouali S, Ben Yahia S, Ladjimi A, Messaoud R, Jenzeri S, Attia S (2005) Anterior ischemic optic neuropathy associated with Rickettsia conorii infection. J Neuroophthalmol 25:212-214

24. Petersen LR, Marfin AA (2002) West Nile virus: a primer for the clinician. Ann Intern Med 137:173-179

25. Nash D, Mostashari F, Fine A et al (2001) The outbreak of West Nile virus infection in the New York City area in 1999. N Engl J Med 344:1807-1814

26. Garg S, Jampol LM (2005) Systemic and intraocular manifestations of West Nile virus infection. Surv Ophthalmol 50:3-13

27. Bains HS, Jampol LM, Caughron MC, Parnell JR (2003) Vitritis and chorioretinitis in a patient with West Nile virus infection. Arch Ophthalmol 121:205-207

28. Vandenbelt S, Shaikh S, Capone A Jr, Williams GA (2003) Multifocal choroiditis associated with West Nile virus encephalitis. Retina 23:97-99

29. Adelman RA, Membreno JH, Afshari NA, Stoessel KM (2003) West Nile virus chorioretinitis. Retina 23:100-101

30. Hershberger VS, Augsburger JJ, Hutchins RK et al (2003) Chorioretinal lesions in nonfatal cases of West Nile virus infection. Ophthalmology 110:1732-1736

31. Khairallah M, Ben Yahia S, Ladjimi A et al (2004) Chorioretinal involvement in patients with West Nile virus infection. Ophthalmology 111:2065-2070

32. Shaikh S, Trese MT (2004) West Nile virus chorioretinitis. Br J Ophthalmol 88:60-1599

33. Eidsness RB, Stockl F, Colleaux KM (2005) West Nile chorioretinitis. Can J Ophthalmol 40:721-724

34. Myers JP, Leveque TK, Johnson MW (2005) Extensive chorioretinitis and severe vision loss associated with West Nile virus meningoencephalitis. Arch Ophthalmol 123:1754-1756

35. Chan CK, Limstrom SA, Tarasewicz DG, Lin SG (2006) Ocular features of West Nile virus infection in North America: a study of 14 eyes. Ophthalmology 113:15391546

36. Seth RK, Stoessel KM, Adelman RA (2007) Choroidal neovascularization associated with West Nile virus chorioretinitis. Semin Ophthalmol 22:81-84

37. Kuchtey RW, Kosmorsky G, Martin D, Lee MS (2003) Uveitis associated with West Nile virus infection. Arch Ophthalmol 121:1648-1649
38. Kaiser PK, Lee MS, Martin DA (2003) Occlusive vasculitis in a patient with concomitant West Nile virus infection. Am J Ophthalmol 136:928-930

39. Khairallah M, Ben Yahia S, Attia S et al (2006) Severe ischemic maculopathy in a patient with West Nile virus infection. Ophthalmic Surg Lasers Imaging 37:240-242

40. Vaispapir V, Blum A, Soboh S, Ashkenazi H (2002) West Nile virus meningoencephalitis with optic neuritis. Arch Intern Med 162:606-607

41. Gilad R, Lampl Y, Sadeh M et al (2003) Optic neuritis complicating West Nile virus meningitis in a young adult. Infection 31:55-56

42. Anninger WV, Lomeo MD, Dingle J et al (2003) West Nile virus associated optic neuritis and chorioretinitis. Am J Ophthalmol 136:1183-1185

43. Anninger W, Lubow M (2004) Visual loss with West Nile virus infection: a wider spectrum of a "new" disease. Clin Infect Dis 38:e55-e56

44. Alpert SG, Fergerson J, Noel LP (2003) Intrauterine West Nile virus: ocular and systemic findings. Am J Ophthalmol 136:733-735

45. Khairallah M, Ben Yahia S, Attia S, Zaouali S, Ladjimi A, Messaoud R (2007) Linear pattern of West Nile virusassociated chorioretinitis is related to retinal nerve fibres organization. Eye 21:952-955

46. Khairallah M, Ben Yahia S, Letaief M, Attia S, Kahloun R, Jelliti B, Zaouali S, Messaoud R (2007) A prospective evaluation of factors associated with chorioretinitis in patients with West Nile virus Infection. Ocul Immunol Inflamm 15(6):435-439

47. Abroug F, Ouanes-Besbes L, Letaief M et al (2006) A cluster study of predictors of severe West Nile virus infection. Mayo Clin Proc 81(1):12-16

48. Jordan I, Briese N, Fischer N et al (2000) Ribavirin inhibits West Nile virus replication and cytopathic effect in neutral cells. J Infect Dis 182:1214-1217

49. Samuel MA, Diamond MS (2005) Alpha/beta interferon protects against lethal West Nile virus infection by restricting cellular tropism and enhancing neuronal survival. J Virol 79:13350-13361

50. Gea-Banacloche J, Johnson RT, Bagic A et al (2004) West Nile virus: pathogenesis and therapeutic options. Ann Intern Med 140:545-553

51. Ellis DS, Simpson DI, Stamford S et al (1979) Rift Valley fever virus: some ultrastructural observations on material from outbreak in Egypt 1977. J Gen Virol 42:329-337

52. Daubney R, Hudson JR, Garnham PC (1931) Enzootic hepatitis or Rift Valley fever: an undescribed virus disease of sheep, cattle and man from East Africa. J Pathol Bacteriol 34:545-579

53. Meegan JM, Watten RH, Laughlin LW (1981) Clinical experience with Rift Valley fever in humans during the 1977 Egyptian epizootic. Contrib Epidemiol Biostat 3:114-123

54. Al-Hazmi A, Al-Rajhi AA, Abboud EB et al (2005) Ocular complications of Rift Valley fever outbreak in Saudi Arabia. Ophthalmology 112:313-318

55. Elwan MS, Sharaf MH, Gameel K et al (1997) Rift Valley fever retinopathy: observations in a new outbreak. Ann Saudi Med 17:377-380 
56. Laughlin LW, Meegan JM, Strausbaugh LJ et al (1979) Epidemic Rift Valley fever in Egypt: observations of the spectrum of human illness. Trans R Soc Trop Med Hyg 73:630-633

57. Mundel B, Gear J (1951) Rift Valley fever: the occurrence of human cases in Johannesburg. S Afr Med J 25:797-800

58. Siam AL, Meegan JM, Gharbawi KF (1980) Rift Valley fever ocular manifestations: observations during the 1977 epidemic in Egypt. Br J Ophthalmol 64:366-374

59. Olaleye OD, Tomori O, Ladipo MA et al (1996) Rift Valley fever in Nigeria: infections in humans. Rev Sci Tech 15:923-935

60. Garcia LL, Crance JM, Billecocq A et al (2001) Quantitative real-time PCR detection of Rift Valley fever virus and its application to evaluation of antiviral compounds. $\mathrm{J}$ Clin Microbiol 39:4456-4461

61. Peters CJ (1998) Harrison's principles of internal medicine, 14th edn. McGraw Hill, New York, pp 1142-1147

62. Peters CJ (2000) Bunyaviridae. In: Principles and practice of infectious disease, 5th edn. Churchill Livingstone, Philadelphia, pp 1849-1855

63. Pollack RJ, Eiszewski AE, Spielman A (2002) Repelling mosquitoes. N Engl J Med 347:2-3

64. World Health Organization (1997) Dengue hemorrhagic fever: diagnosis, treatment and control, 2nd edn. WHO, Geneva, Switzerland

65. Ministry of Health, Singapore (2004) Communicable Diseases Surveillance in Singapore 2003. Ministry of Health, Singapore, p 105. http://www.moh.gov.sg/corp/ publications/CDS2003. Accessed 2 Mar 2007

66. Wen KH, Sheu MM, Chung CB, Wang HZ, Chen CW (1989) The ocular fundus findings in dengue fever. Gaoxiong Yi Xue Ke Xue Za Zhi 5:24-30

67. Haritoglou C, Scholz F, Bialaslewicz A, Klauss V (2000) Ocular manifestations in dengue fever. Ophthalmologe 97:433-436 (In German)

68. Haritoglou C, Dotse SD, Rudolph G, Stephan CM, Thurau SR, Klauss V (2002) A tourist with dengue fever and visual loss. Lancet 360:1070

69. Lim WK, Mathur R, Koh A, Yeoh R, Chee SP (2004) Ocular manifestations of dengue fever. Ophthalmology 111:2057-2064

70. Chlebicki MP, Ang B, Barkham T, Laude A (2005) Retinal haemorrhages in 4 patients with dengue fever. Emerg Infect Dis (Serial on the Internet). http://www.cdc. gov/ncidod/EID/vol11/n005/04-0992.htm

71. The Eye Institute Dengue-Related Ophthalmic Complications Workgroup (2006) Ophthalmic complications of dengue. Emerg Infect Dis (Serial on the Internet). http://www.cdc.gov.ncidod/EID/vol12no02/05-0274.htm

72. Bacsal K, Chee SP, Cheng CL, Flores JVPG (2007) Dengue-associated maculopathy. Arch Ophthalmol 125: 501-510

73. Kapoor HK, Bhai S, John M, Xavier J (2006) Ocular manifestations of dengue fever in an East Indian epidemic. Can J Ophthalmol 41:741-746

74. Mehta S (2005) Ocular lesions in severe dengue hemorrhagic fever (DHF). J Assoc Phys India 53:656-657
75. Cruz-Villegas V, Berrocal AM, Davis JL (2003) Bilateral choroidal effusions associated with dengue fever. Retina 23:576-578

76. Siqueira RC, Vitral NP, Campos WR, Orefice F, de Moraes Figueiredo LT (2004) Ocular manifestations in dengue fever. Ocul Immunol Inflamm 12:251-254

77. Su DHW, Bacsal K, Chee SP et al (2007) Prevalence of dengue maculopathy in patients hospitalized for dengue fever. Ophthalmology 114:1743-1747

78. RE Johnston, CJ Peters (1996) Alphaviruses. In: Fields BN, Knipe DM, Howley PM (eds) Fields virology, 3rd edn, vol 1. Lippincott-Raven Publishers, Philadelphia, pp 858-898

79. WHO Disease Outbreak News (2006) Chikungunya and dengue in the south west Indian Ocean. http://www.who. int/csr/don/2006_03_17/en. Accessed 17 Mar 2006

80. Borgherini G, Poubeau P, Staikowsky F et al (2007) Outbreak of chikungunya on Reunion Island: early clinical and laboratory features in 157 adult patients. Clin Infect Dis 44:1401-1407

81. Centers for Disease Control and Prevention (2006) Outbreak notice: chikungunya fever in India. http://www.cdc. gov/travel/other/2006/chikungunya_india.htm. Accessed 19 June 2006

82. Ligon BL (2006) Reemergence of an unusual disease: the chikungunya epidemic. Semin Pediatr Infect Dis 17:99104

83. Quatresous I, the Investigation Group (2006) E-alert 27 January: (2006) Chikungunya outbreak in Réunion, a French 'overseas département'. Euro Surveill 11:E0602 02.1. http://www.eurosurveillance.org/ew/2006/060202

84. Paquet C, Quatresous I, Solet J et al (2006) Chikungunya outbreak in Reunion: epidemiology and surveillance, 2005 to early January 2006. Euro Surveill 11:E060202E060203

85. Mohan A (2006) Chikungunya fever: clinical manifestations \& management. Indian J Med Res 124:471-474

86. Arankalle VA, Shrivastava S, Cherian S et al (2007) Genetic divergence of Chikungunya viruses in India (1963-2006) with special reference to the 2005-2006 explosive epidemic. J Gen Virol 88:1967-1976

87. Chhabra M, Mittal V, Bhattacharya D et al (2008) Chikungunya fever: a re-emerging viral infection. Indian $\mathbf{J}$ Med Microbiol 26:5-12

88. Angelini R, Finarelli A, Angelini P et al (2007) An outbreak of chikungunya fever in the province of Ravenna, Italy. Euro Surveill. 12(9):E070906. http://www.eurosur veillance.org/ew/2007/070906

89. Chikungunya Fever Fact Sheet (2006) CDC Division of vector borne infectious diseases. http://www.cdc.gov/ ncidod/chikungunya/chickfact.htm.2006

90. Hochedez P, Hausfater P, Jaureguiberry S et al (2007) Cases of chikungunya fever imported from the islands of the South West Indian Ocean to Paris, France. Euro Surveill 12(1) [Epub ahead of print]. http://www. eurosurveillance.org/em/v12n01/1201-227

91. Taubitz W, Cramer JP, Kapaun A et al (2007) Chikungunya fever in travelers: clinical presentation and course. Clin Infect Dis 45(1):e1-4. Epub 2007 May 23 
92. Schuffenecker I, Iteman I, Michault A et al (2006) Genome microevolution of Chikungunya viruses causing the Indian Ocean outbreak. PLoS Med 23:e263

93. Pialoux G, Gaüzère B-A, Jauréguiberry S et al (2007) Chikungunya, an epidemic arbovirosis. Lancet Infect Dis 7:319-327

94. Kalantri SP, Joshi R, Riley LW (2006) Chikungunya epidemic: an Indian perspective. Natl Med J India 19:315-322

95. Kennedy AC, Fleming J, Solomon L et al (1980) Chikungunya viral arthropathy: a clinical description. J Rheumatol 7:231-236

96. Fourie ED, Morrison JG (1979) Rheumatoid arthritic syndrome after chikungunya fever. S Afr Med J 56:02130

97. Simon F, Parola P, Grandadam M, Fourcade S et al (2007) Chikungunya infection: an emerging rheumatism among travelers returned from Indian Ocean islands. Report of 47 cases. Medicine (Baltimore) 86:123-137

98. Halstead SB (2004) Chikungunya. In: Feigin RD, Cherry JD, Demmler GJ (eds) Textbook of pediatric infectious diseases, 5th edn. Saunders, Philadelphia, pp 2178-2184

99. Wielanek AC, Monredon JD, Amrani ME et al (2007) Guillain-Barré syndrome complicating a Chikungunya virus infection. Neurology 27:2105-2107

100. Chatterjee SN, Chakravarti SK, Mitra AC et al (1965) Virological investigation of cases with neurological complications during the outbreak of haemorrhagic fever in Calcutta. J Indian Med Assoc 45:314-316

101. Mazaud R, Salaun JJ, Montabone H et al (1971) Acute neurologic and sensorial disorders in dengue and chikungunya fever. Bull Soc Pathol Exot Filiales 64:22-30

102. Mittal A, Mittal S, Bharati MJ et al (2007) Optic neuritis associated with chikungunya virus infection in South India. Arch Ophthalmol 125:1381-1386

103. Lalitha P, Rathinam S, Banushree K et al (2007) Ocular involvement associated with an epidemic outbreak of chikungunya virus infection. Am J Ophthalmol 144:552-556

104. Mahendradas P, Ranganna SK, Shetty R et al (2007) Ocular manifestations associated with Chikungunya. Ophthalmology Jul 11 [Epub ahead of print]

105. Mittal A, Mittal S, Bharathi JM et al (2007) Uveitis during outbreak of Chikungunya fever. Ophthalmology 114:1798
106. Chanana B, Azad RV, Nair S et al (2007) Bilateral macular choroiditis following Chikungunya virus infection. Eye 21:020-021

107. Nimmannitya S, Halstead SB, Cohen SN et al (1969) Dengue and chikungunya virus infection in man in Thailand, 1962-1964. I. Observations on hospitalized patients with hemorrhagic fever. Am J Trop Med Hyg 18:954-971

108. Ravi V (2006) Re-emergence of chikungunya virus in India. Indian J Med Microbiol 24:83-84

109. Thiruvengadam KV, Kalyanasundaram V, Rajgopal J (1965) Clinical and pathological studies on chikungunya fever in Madras city. Indian J Med Res 53(8):729-744

110. Sarkar JK, Pavri KM, Chatterjee SN et al (1964) Virological and serological studies of cases of haemorrhagic fever in Calcutta: Material collected from Calcutta School of Tropical Medicine. Indian J Med Res 52:684-691

111. Shah KV, Gibbs CJ Jr et al (1964) Virological investigation of the epidemic of haemorrhagic fever in Calcutta: isolation of three strains of Chikungunya virus. Indian J Med Res 52:676-683

112. Myers RM, Cary DE, Reuben R et al (1965) The 1964 epidemic of dengue-like fever in South India: Isolation of Chikungunya virus from human sera and from mosquitoes. Indian J Med Res 53:694-701

113. Rohani A, Yulfi H, Zamree et al (2005) Rapid detection of chikungunya virus in laboratory infected Aedes aegypti by Reverse-Transcriptase-Polymerase Chain Reaction (RT-PCR). Trop Biomed 22:5-149

114. Pfeffer M, Linssen B, Parke MD et al (2002) Specific detection of chikungunya virus using a RT-PCR/nested PCR combination. J Vet Med B Infect Dis Vet Public Health 49:49-54

115. Hasebe F, Parquet MC, Pandey BD, Balasubramaniam V et al (2002) Combined detection and genotyping of Chikungunya virus by a specific reverse transcription polymerase chain reaction. J Med Virol 67:370-374

116. Pastorino B, Bessaud M, Grandadam M et al (2005) Development of a TaqMan RT-PCR assay without RNA extraction step for the detection and quantification of African Chikungunya viruses. J Virol Methods 124:65-71 